\title{
BMJ Open Training and redeployment of healthcare workers to intensive care units (ICUs) during the COVID-19 pandemic: a systematic review
}

Norha Vera San Juan (D , , ${ }^{1,2}$ Sigrún Eyrúnardóttir Clark, ${ }^{1}$ Matthew Camilleri, ${ }^{3,4}$ John Paul Jeans, ${ }^{3,5}$ Alexandra Monkhouse, ${ }^{3,6}$ Georgia Chisnall (D) , ${ }^{1}$ Cecilia Vindrola-Padros (iD ${ }^{1}$

To cite: Vera San Juan N, Clark SE, Camilleri M, et al. Training and redeployment of healthcare workers to intensive care units (ICUs) during the COVID-19 pandemic: a systematic review. BMJ Open 2022;12:e050038. doi:10.1136/ bmjopen-2021-050038

- Prepublication history and additional supplemental material for this paper are available online. To view these files, please visit the journal online (http://dx.doi.org/10.1136/ bmjopen-2021-050038).

Received 08 February 2021 Accepted 09 December 2021

Check for updates

(C) Author(s) (or their employer(s)) 2022. Re-use permitted under CC BY-NC. No commercial re-use. See rights and permissions. Published by BMJ.

For numbered affiliations see end of article.

Correspondence to Cecilia Vindrola-Padros; c.vindrola@ucl.ac.uk

\section{ABSTRACT}

Objectives The rapid influx of patients with COVID-19 to intensive care at a rate that exceeds pre-existing staff capacity has required the rapid development of innovative redeployment and training strategies, which considered patient care and infection control. The aim of this study was to provide a detailed understanding of redeployment and training during the first year of the COVID-19 pandemic by capturing and considering the merit of the strategies enlisted and the experiences and needs of redeployed healthcare workers (HCWs).

Design The review involved a systematic search of key terms related to intensive care AND training AND redeployment AND healthcare workers within nine databases (Medline, CINAHL, PsychINFO, MedRxiv, Web of Science, The Health Management Consortium database, Social Science Research Network, OpenGrey and TRIP), which took place on 16 July 2021. Analysis consisted of a synthesis of quantitative study outputs and frameworkbased thematic analysis of qualitative study outputs and grey literature. These results were then combined applying an interpretative synthesis. We followed Preferred Reporting Items for Systematic Reviews and Meta-Analyses, and the review protocol was available online.

Results Forty papers were analysed. These took place primarily in the UK $(n=15,37.5 \%)$ and USA $(n=17,42.5 \%)$. Themes presented in the results are redeployment: implementation strategies and learning; redeployed HCWs' experience and strategies to address their needs; redeployed HCWs' learning needs; training formats offered and training evaluations; and future redeployment and training delivery. Based on this, key principles for successful redeployment and training were proposed.

Conclusions The COVID-19 pandemic presents unique challenges to develop flexible redeployment strategies and deliver training promptly while following infection control recommendations. This review synthesises original approaches to tackle these challenges, which are relevant to inform the development of targeted and adaptative training and redeployment plans considering the needs of HCWs.

\section{Strengths and limitations of this study}

- This is the first review to capture the redeployment and training strategies enlisted during the first year of the COVID-19 pandemic and the needs of redeployed healthcare workers (HCWs).

- The study took the form of a systematic review that synthesised 40 papers identified across nine databases.

- Papers included research studies $(n=21)$, commentaries $(n=12)$ and reports or guidelines $(n=7)$, which were predominantly from the UK $(n=15)$ and USA $(n=17)$ (limiting the exploration of redeployment in low-income and middle-income countries).

> Themes were identified through conducting a synthesis on quantitative study outputs and thematic synthesis on qualitative study outputs, followed by combining the analyses through interpretive synthesis.

- Searches were limited to nine databases and restricted from December 2019 to 16 July 2021. The review will have missed literature published outside of these dates and not included in these databases.

\section{INTRODUCTION}

To accommodate for the rapid fluctuations in the number of patients with COVID-19, healthcare organisations have been forced to optimise resource and staff allocation procedures. The unprecedented increase in the demand for intensive care services due to the COVID-19 pandemic involved the rapid redeployment of healthcare workers (HCWs) to these units. This posed multiple challenges, including devising new ways of working and rapid development and delivery of training. This review aimed to document key aspects of redeployment implementation, HCWs' experiences and training.

Redeployment of HCWs from other specialties to intensive care can be used to achieve the sustainable delivery of patient care. ${ }^{12}$ 
Redeployment can be used to facilitate the daily work of intensive care units (ICU) when implementing task-based models, where key tasks of patient care (ie, hygiene) are carried out promptly by competent redeployed HCWs. ${ }^{3}$ Staff redeployment can also help to address staffing gaps caused by staff sickness and previous vacancies.

Building HCWs' competence and confidence is an essential principle of safe redeployment. ${ }^{4}$ Induction training must be provided to reacquaint redeployed HCWs with ICU ward multidisciplinary team practice, introduce them to clinical practices to care for COVID-19 patients and adequate use of personal protective equipment (PPE). ${ }^{5}$ Time constraints and infection control measures pose unprecedented logistical challenges for training delivery, with traditional training methods such as those imparted in classrooms or at conferences not being possible. The impact of redeployment on HCW well-being has also been identified. ${ }^{67}$ Redeployed HCWs have expressed concern in relation to their safety, the impact of their work on family members (including infecting them with the virus) and their own training and career progression. ${ }^{68}$

A range of novel strategies to implement redeployment and share knowledge in the context of the pandemic have been proposed and trialled. ${ }^{9}$ Gaining a detailed understanding of what worked and the unmet needs of HCWs will facilitate the development of redeployment plans for this pandemic as well as future ones.

\section{Aim}

The aim of this review was to provide a detailed understanding of the characteristics of redeployment to ICU and training provision during the first year and a half of the COVID-19 pandemic. It sought to identify what worked in redeployment and training, and concerns regarding future redeployment planning.

The research questions guiding the review were:

- What were the main strategies developed to redeploy HCWs to ICU?

- What were the principles of redeployment?

- What were redeployed HCWs' experiences and perceived training needs?

- Were these needs addressed? If so, how? If not, why not?

- What were the areas of good practice identified for both redeployment and training?

\section{METHODS}

This review followed the Preferred Reporting Items for Systematic Reviews and Meta-Analyses (PRISMA) statement, ${ }^{10}$ and a protocol was developed a priori. The protocol was published on the authors' institutional website (see online supplemental material 1) as it was not eligible for publication on PROSPERO.

\section{Eligibility criteria}

Studies and commentaries published in peer-reviewed journals or official reports were included in this review if they focused on training or redeployment to ICUs and related wards during COVID-19. The publication dates were restricted from December 2019 to 16 July 2021. There were no restrictions on language.

Articles were excluded if the focus was on redeployment to other areas of care, other viral infection emergencies or changes in healthcare activities such as shifting to remote working.

\section{Search strategy and study selection}

Nine electronic databases were searched in December 2020 and again in July 2021 (including peer-reviewed and grey literature): Medline, CINAHL, PsychINFO, MedRxiv, Web of Science, The Health Management Consortium database, Social Science Research Network, OpenGrey and TRIP. The search strategy consisted of key terms referring to intensive care AND training AND redeployment AND healthcare workers. The search strategy was simplified when necessary for grey literature databases. A complete search strategy is provided in online supplemental material 2.

Search results were imported into Rayyan ${ }^{11}$ and deduplicated. Title and abstract screening was conducted independently by two researchers (CV and NVSJ for the first search, SEC and GC for the second search), and discrepancies were resolved via discussion until consensus was reached. Full texts of articles deemed relevant for inclusion were then screened against full review eligibility criteria. The references of included full-text articles were reviewed to identify additional articles. In the event that non-English papers were identified, members of the broader team who spoke the language were asked to review these.

\section{Data extraction and risk of bias assessment}

NVSJ and SEC extracted the information of the articles using a data extraction form developed on Qualtrics based on a predefined list of data (see box 1). The sections of the list relevant to redeployment and training were created after a preliminary scan of the selected articles.

Study details such as setting, population and methodological characteristics were collected from all articles. The core findings collected from the studies included details of redeployment experiences and implementation strategies (research question 1) and

\section{Box 1 List of data extracted from articles}

Paper information: full citation; type of entry; and location.

- Study aims.

> Population.

- Study design: data collection and analysis methods.

- Redeployment: factors that determine redeployment; redeployment objectives; implementation strategies; redeployed HCWs' experience; redeployment learnings; and redeployed HCWs' needs.

- Training: training programme offered; programme evaluation; pre/ post results; and what worked. 
training programmes offered (research question 2). Special attention was paid to extract information about lessons learnt and concerns for the future.

We expected a heterogeneous group of studies using different questions and outcomes; therefore, the Authority, Accuracy, Coverage, Objectivity, Date, Significance checklist $^{12}$ was applied during data extraction to assess the veracity of the source, clarity of the methods, acknowledgement of bias and the relevance of the contribution to the field.

\section{Data synthesis method}

We conducted a narrative synthesis of the study characteristics and quantitative study outputs ${ }^{13}$ and a framework-based thematic analysis of qualitative study outputs and grey literature. ${ }^{1415}$ Quantitative and qualitative results were combined using an interpretative synthesis to develop an understanding of how they related and answer the research questions. ${ }^{16} 17$ The interpretive synthesis was based on identifying emerging patterns, or lines of argument, across studies by repeatedly comparing them, and integrating these lines of argument interpretatively to provide a bigger picture. ${ }^{17}$

\section{Patient and public involvement}

No ICU patients were involved in the development of this study; however, all authors had first-hand experience of being infected or having close relatives and friends who were infected with COVID-19. The development of the research question and interpretation of the findings was informed by MC, JPJ and AM, who worked as clinicians and training providers during this pandemic. An infographic was developed to facilitate the dissemination of findings outside of academic settings.

\section{RESULTS}

\section{Study selection}

The screening and selection process is presented below in figure 1 according to the PRISMA guidelines.

At full-text screening stage, 41 articles were excluded as these did not include information relevant to the research questions; were not specific to redeployed HCWs; or were abstract pieces from conferences.

\section{Study characteristics}

From the 40 papers included in this systematic review, 21 $(52.5 \%)$ were research studies; $12(30 \%)$ were opinion pieces or commentaries; and $7(17.5 \%)$ were reports or guidelines. Papers were primarily from the UK $(n=15$, $37.5 \%)$ and USA ( $\mathrm{n}=17,42.5 \%)$. Other locations included China, India, Belgium, Italy, Germany and France and two studies involving multiple countries. Fourteen (35\%) studies focused on redeployment implementation and experiences of redeployed HCWs exclusively and $26(65 \%)$ on training delivery and evaluation, and dissemination of knowledge. The professional groups that were considered included nurses, physician assistants, anaesthetists, otolaryngologists, ophthalmologists, paramedics, radiologists, urologists, neurologists, orthopaedic surgeons, pharmacy residents, junior doctors, physical therapists, occupational therapists and physiotherapists.

From the 21 research studies included in the review, sample sizes ranged from $10^{18}$ to $2527 . .^{19}$ One study reported 59\% ( $\mathrm{n}=19)$ of participants were male, and $41 \%$ $(n=13)$ female, ${ }^{20}$ while another study reported that the majority of the participants were female $(70.8 \%, n=17) .{ }^{21}$ Other participant demographic characteristics such as ethnicity were not provided.

Of the studies, 35 met $75 \%$ or more of the quality criteria assessed as these were written by recognised experts, included reference lists, targeted a clear aim and stated details such as date, location and limitations. However, five of the studies only met $50 \%-70 \%$ of the criteria as they did not have a clear aim and methodology or did not identify bias.

A full summary of the studies included in this review can be found in table 1 .

\section{Synthesis}

Findings from this review are presented under the headings redeployment: implementation strategies and learnings; redeployed HCWs' experience and strategies to address their needs; redeployed HCWs' learning needs; training formats offered and training evaluations and distilled in a final section where we propose key principles for successful redeployment.

Table 2 provides a summary of the themes and their description.

\section{Theme 1: redeployment: implementation strategies}

Due to the shifting nature of the pandemic, areas of need were moving targets that constantly changed. ${ }^{22}$ Redeployment varied depending on the individual institution configuration, geographical and population context and stage of the pandemic. ${ }^{2}$ Strategies to redistribute HCWs to meet surge demands varied across countries and health systems. In terms of sources from which to redeploy HCWs, for example, most places had access to volunteers for internal redeployment. Some of the places with the greatest burden of COVID-19 cases recruited from outside of the health system (eg, travelling nurses). ${ }^{23}$

Clear decision-making processes were facilitated, for example, by clear definitions of 'urgent' and efficient channelling of information to create a clear and consistent message. ${ }^{24}{ }^{25}$ For the latter, suggestions included limiting the use of email chains, using online platforms such as Dropbox or apps like Induction of Clinbee, and bespoke WhatsApp groups. ${ }^{25-29}$ In the UK, Regional Emergency Preparedness Response and Resilience (EPRR) teams were reported as key to assisting hospitals in the management of acute surges. Clinicians and managers were advised to define warning triggers to anticipate a surge and establish communication lines with EPRR teams. ${ }^{2}$ Healthcare settings also made efforts to enable two-way 


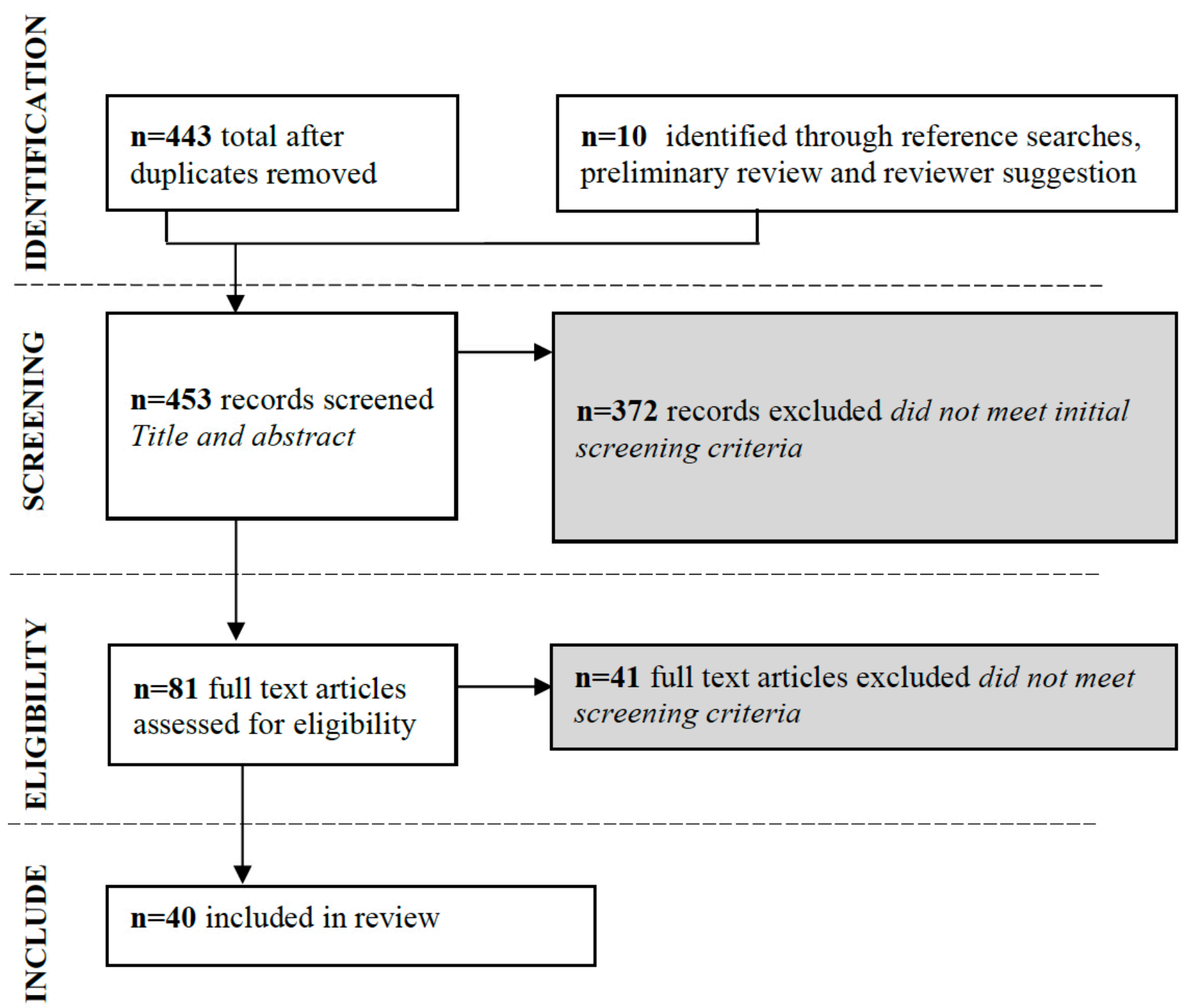

Figure 1 Preferred Reporting Items for Systematic Reviews and Meta-Analyses (PRISMA) flow diagram of the screening and selection process conducted in this systematic review.

communication to allow for feedback from redeployed HCWs through webinars, briefing meetings and feedback forms. ${ }^{25262830}$ Transparency and involvement of frontline clinicians as stakeholders were important components and helped to maintain trust among HCWs. ${ }^{31}$

Redeployment planning aimed to minimise training needs and maximise the use of redeployed HCWs' previous knowledge by placing HCWs in roles where their existing skills could be more easily transferrable. ${ }^{325} 3032$ Panda et al found that health system leaders (ie, chief medical officers, chairs or division chiefs) favoured a decentralised leadership approach, where organisationwide goals were disseminated to frontline leaders for implementation. This facilitated targeted training, as local leaders were better able to identify the training needs of each redeployee. A successful approach to redeployment was allocating redeployed HCWs to designated treatment teams, that is task-based groups made up of multidisciplinary teams with clear leadership and constant communication that aimed to complete a specific necessary step of intensive care when requested by experienced ICU HCWs. ${ }^{2} 25272831$ 33-37 Another successful strategy was a tiered staffing model where critical care trained physicians or nurses oversaw non-ICU clinicians. ${ }^{31}$ This represented an important shift in ways of working and understanding collaborations between health specialists. ${ }^{3}$ There were benefits in some specialists taking over ICU roles, examples of this were otolaryngologists examining epistaxis, peritonsillar abscess and facial trauma ${ }^{22}$; experienced renal physicians, together with trainee radiologists developing line insertion teams or orthopaedists and physiotherapists assisting with proning. ${ }^{3}$ Benefits included the reduction of personnel required for procedures, reduction of aerosolisation of the virus, shorter time dedicated to procedures and minimal or no training required for them to provide assistance. 
Table 1 . Characteristics of the included articles

\section{First author}

NHS England and Report/guideline UK

NHS Improvement

$(\mathrm{a})^{2}$

Camilleri et al ${ }^{46} \quad$ Scientific paper UK and Ireland

Article focus

Study design

Study population

Management of

N/A

N/A

surges: redeployment

and training

\begin{tabular}{|c|c|c|c|c|c|}
\hline 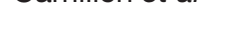 & 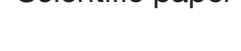 & 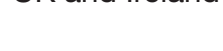 & learning course & questionnaire design & physiotherapists \\
\hline George et $a l^{24}$ & Scientific paper & USA & $\begin{array}{l}\text { Redeployment and } \\
\text { training of cardiac } \\
\text { surgery practice }\end{array}$ & Review & $\begin{array}{l}\text { Cardiac surgery } \\
\text { divisions }\end{array}$ \\
\hline Doussot et $\left.a\right|^{33}$ & Scientific paper & France & $\begin{array}{l}\text { Redeployment } \\
\text { feasibility and safety }\end{array}$ & $\begin{array}{l}\text { Quantitative: } \\
\text { prospective cohort } \\
\text { study }\end{array}$ & Healthcare workers \\
\hline
\end{tabular}

$\begin{array}{llll}\text { Doyle et } \mathrm{a}^{3} & \begin{array}{l}\text { Opinion piece/ } \\ \text { commentary }\end{array} & \text { England } & \begin{array}{l}\text { Experiences of } \\ \text { redeploying medical } \\ \text { staff }\end{array} \\ \text { Jansen et } a l^{48} & \text { Scientific paper } & \text { Germany } & \begin{array}{l}\text { A blended learning } \\ \text { concept }\end{array}\end{array}$

N/A N/A

Mixed methods: Medical personnel questionnaire design without ICU or

Emergency Room (ER) training

\begin{tabular}{|c|c|c|c|c|c|}
\hline Nair et al & Report/ guideline & USA & $\begin{array}{l}\text { Simulation-based } \\
\text { training }\end{array}$ & N/A & N/A \\
\hline Lim et $a l^{41}$ & Scientific paper & UK & $\begin{array}{l}\text { Redeployment of } \\
\text { ophthalmologists }\end{array}$ & $\begin{array}{l}\text { Quantitative: survey } \\
\text { design }\end{array}$ & Ophthalmologists \\
\hline $\begin{array}{l}\text { Shipchandler et } \\
\mathrm{al}^{22}\end{array}$ & $\begin{array}{l}\text { Opinion piece/ } \\
\text { commentary }\end{array}$ & USA & $\begin{array}{l}\text { Role of } \\
\text { otolaryngologists in } \\
\text { redeployment }\end{array}$ & N/A & N/A \\
\hline Marks et al ${ }^{18}$ & Scientific paper & USA & $\begin{array}{l}\text { Rapid deployment } \\
\text { of critical care nurse } \\
\text { education }\end{array}$ & $\begin{array}{l}\text { Qualitative: interview } \\
\text { design }\end{array}$ & Nurses \\
\hline Kuang et $a l^{44}$ & Scientific paper & China & $\begin{array}{l}\text { Redeployment and } \\
\text { training of non- } \\
\text { specialists }\end{array}$ & $\begin{array}{l}\text { Quantitative: cohort } \\
\text { study }\end{array}$ & $\begin{array}{l}\text { 1. Non-specialists } \\
\text { 2. Specialists }\end{array}$ \\
\hline D'souza et $a 4^{40}$ & Report/guideline & India & $\begin{array}{l}\text { Adapting a secondary } \\
\text { hospital for COVID-19 }\end{array}$ & N/A & $\mathrm{N} / \mathrm{A}$ \\
\hline Brickman et al & Scientific paper & USA & $\begin{array}{l}\text { Rapid critical care } \\
\text { training for nurses }\end{array}$ & Not specified & Nurses \\
\hline Naik et al & Scientific paper & USA & $\begin{array}{l}\text { Telesimulation training } \\
\text { for COVID-19 ventilator } \\
\text { management }\end{array}$ & Not specified & $\begin{array}{l}\text { Hospitalists, } \\
\text { emergency medicine } \\
\text { physicians and } \\
\text { physician assistants, } \\
\text { paediatric residents, } \\
\text { nurses and a nurse } \\
\text { educator }\end{array}$ \\
\hline
\end{tabular}

Continued 
Table 1 Continued

\section{First author

name Type of paper Location

NHS England and Report/guideline UK NHS Improvement

(b) ${ }^{4}$

$\begin{array}{lll}{\text { Hettle et } a l^{1}} & \text { Scientific paper } & \text { UK } \\ {\text { Bohmer et } a l^{26}}^{\text {Opinion piece/ }} & \text { UK } \\ \text { commentary } & \end{array}$

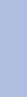

Khusid et $\left.a\right|^{38} \quad$ Scientific paper USA

$\begin{array}{lll}\text { Shi et } a l^{27} & \text { Scientific paper USA } \\ \text { KCE Belgian } & \text { Report/guideline } & \text { Belgium } \\ \text { Health Care } & & \\ \text { Knowledge } & & \\ \text { Centre }^{32} & & \end{array}$

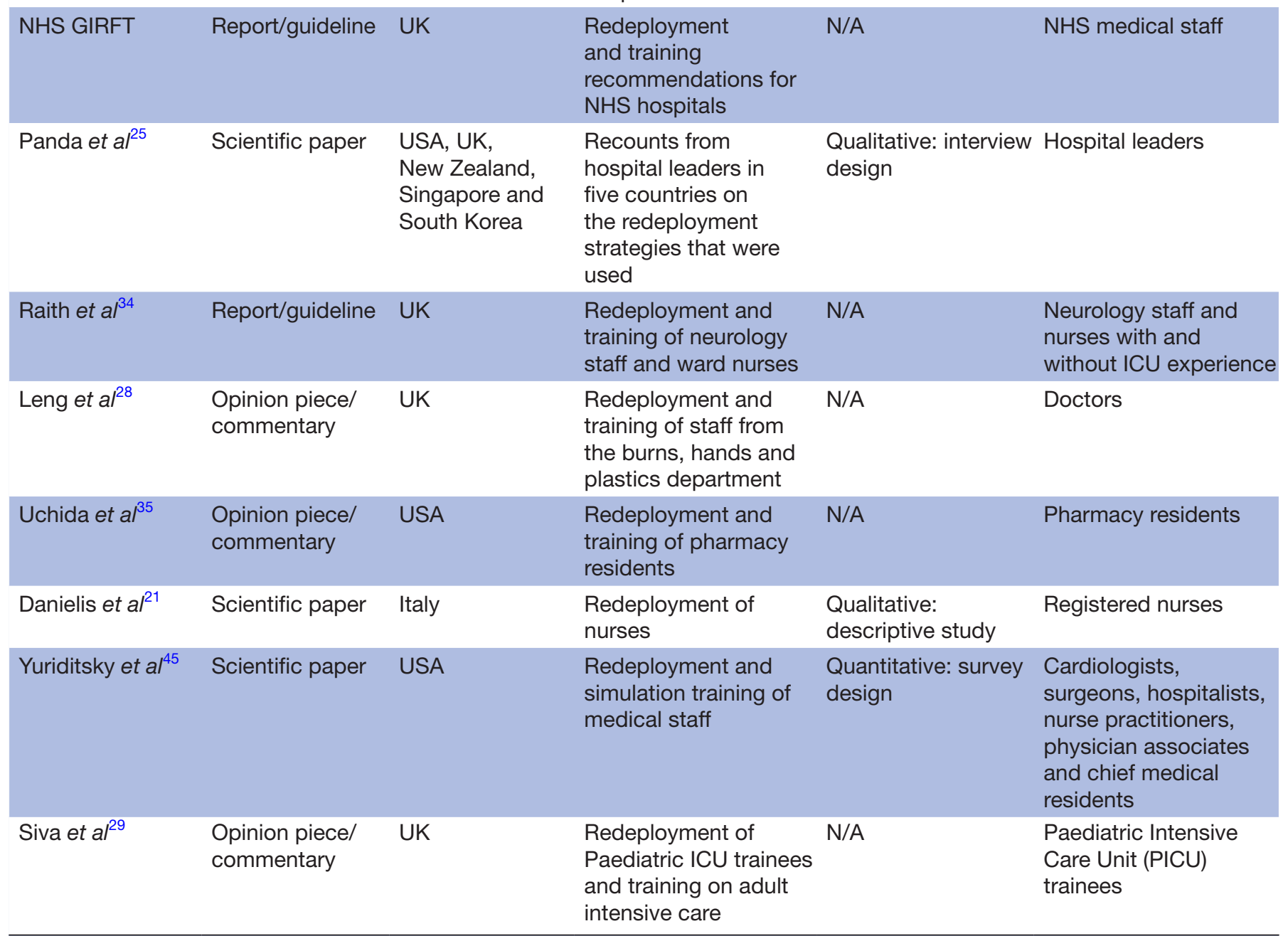

Continued

\section{Article focus}

Study design

Study population

Redeployment and

N/A

N/A

safety

Cross-skill training and Mixed methods:

Doctors

redeployment

questionnaire design

Learning system to
manage workforce and
training of redeployed
staff

Redeployment of urology residents

\section{Redeployment and} training of radiology trainees

Quantitative: questionnaire design

Quantitative: Radiology trainees

retrospective interventional study

Redeployment and N/A Medical staff training strategies throughout Belgian hospitals

Redeployment N/A

Redeployed staff with ICU experience and volunteers with and without clinical experience

Urology residents

(b) 4 recommendations for NHS hospitals

Recounts from the redeployment strategies that were nurses with and without ICU experience

Redeployment and Redeployment and residents

\section{Redeployment of}

Redeployment and Quantitative: survey nurse practitioners, sidents Care Unit (PICU) intensive care 
Table 1 Continued

\begin{tabular}{|c|c|c|c|c|c|}
\hline $\begin{array}{l}\text { First author } \\
\text { name }\end{array}$ & Type of paper & Location & Article focus & Study design & Study population \\
\hline Ch'ang et $a^{39}$ & Scientific paper & USA & $\begin{array}{l}\text { Video based learning } \\
\text { curriculum to teach } \\
\text { critical care concepts } \\
\text { to neurology trainees }\end{array}$ & $\begin{array}{l}\text { Interventional study } \\
\text { with quantitative } \\
\text { survey design }\end{array}$ & Neuroscience trainees \\
\hline Hickey et $\left.a\right|^{36}$ & $\begin{array}{l}\text { Opinion piece/ } \\
\text { commentary }\end{array}$ & USA & $\begin{array}{l}\text { Redeployment of } \\
\text { registered nurses and } \\
\text { emergency department } \\
\text { nurses }\end{array}$ & N/A & $\begin{array}{l}\text { Registered nurses and } \\
\text { emergency department } \\
\text { nurses }\end{array}$ \\
\hline DiMaggio et al & Scientific paper & USA & $\begin{array}{l}\text { Impact of } \\
\text { redeployment on } \\
\text { mental health of staff }\end{array}$ & $\begin{array}{l}\text { Quantitative: survey } \\
\text { design }\end{array}$ & $\begin{array}{l}\text { Physicians, nurse } \\
\text { practitioners and } \\
\text { physician associates }\end{array}$ \\
\hline Robinson et al ${ }^{47}$ & $\begin{array}{l}\text { Opinion piece/ } \\
\text { commentary }\end{array}$ & UK & $\begin{array}{l}\text { Redeployment and } \\
\text { training of respiratory } \\
\text { and infectious disease } \\
\text { healthcare staff to a } \\
\text { new ward-based team }\end{array}$ & N/A & $\begin{array}{l}\text { Respiratory and } \\
\text { infectious disease } \\
\text { healthcare staff }\end{array}$ \\
\hline Wells et $a l^{30}$ & $\begin{array}{l}\text { Opinion piece/ } \\
\text { commentary }\end{array}$ & USA & $\begin{array}{l}\text { Redeployment and } \\
\text { training of nurses, } \\
\text { technologists and } \\
\text { existing ICU staff }\end{array}$ & N/A & $\begin{array}{l}\text { Registered nurses and } \\
\text { technologists }\end{array}$ \\
\hline Khajuria et al ${ }^{19}$ & Scientific paper & 41 countries & $\begin{array}{l}\text { Impact of } \\
\text { redeployment and } \\
\text { training on mental } \\
\text { health of staff }\end{array}$ & $\begin{array}{l}\text { Cross-sectional } \\
\text { study with } \\
\text { quantitative survey } \\
\text { design }\end{array}$ & $\begin{array}{l}\text { Doctors, nurses and } \\
\text { allied healthcare } \\
\text { professionals }\end{array}$ \\
\hline Chiu et $a l^{37}$ & Scientific paper & USA & $\begin{array}{l}\text { Review of the methods } \\
\text { and training used to } \\
\text { develop the Prone } \\
\text { Team using redeployed } \\
\text { staff }\end{array}$ & N/A & $\begin{array}{l}\text { Physical and } \\
\text { occupational therapists } \\
\text { and registered nurses }\end{array}$ \\
\hline
\end{tabular}

ICU, intensive care unit; NHS, National Health Service.

A key barrier for successful redeployment planning was not being able to measure the need of human resources, that is, identifying which specific roles were in demand and which members of the workforce were available and healthy. ${ }^{23}$

Theme 2: redeployed HCWs' experiences and strategies to address their needs

Increasing staff buy-in was key for redeployment to work. Redeployed HCWs experienced anxiety and stress, particularly when lacking adequate support or PPE, during night shifts when fewer HCWs were available and due to last minute rota changes. ${ }^{19} 2124$ 28-30 32 37-39 HCW wellbeing needs that required attention included accommodation, food subsidisation, access to clean scrubs, parking, a 24-hour PPE hotline, testing and family responsibilities. ${ }^{2425303840} \mathrm{Lim}$ et $a l^{4141}$ reported that redeployed ophthalmologists' anxiety reduced once their redeployment role began. This was attributed to receiving support from HCWs in the redeployed area, the sufficient availability of PPE and adequate training. Some HCWs often felt that the redeployment period had encouraged them to learn and change their ways of thinking in challenging situations. ${ }^{21} 26$

Coughlan $e t a l^{4242}$ described solutions for stressors that junior doctors experienced due to working in unfamiliar ICU settings. The interpersonal communication required for intense multidisciplinary teamwork was facilitated by visual aids, anonymised whiteboards and the use of walkietalkies. Worries about potential negligence proceedings resulting from working beyond their usual competencies were mitigated by emergency legislation to protect doctors. 
Table 2 Summary of findings

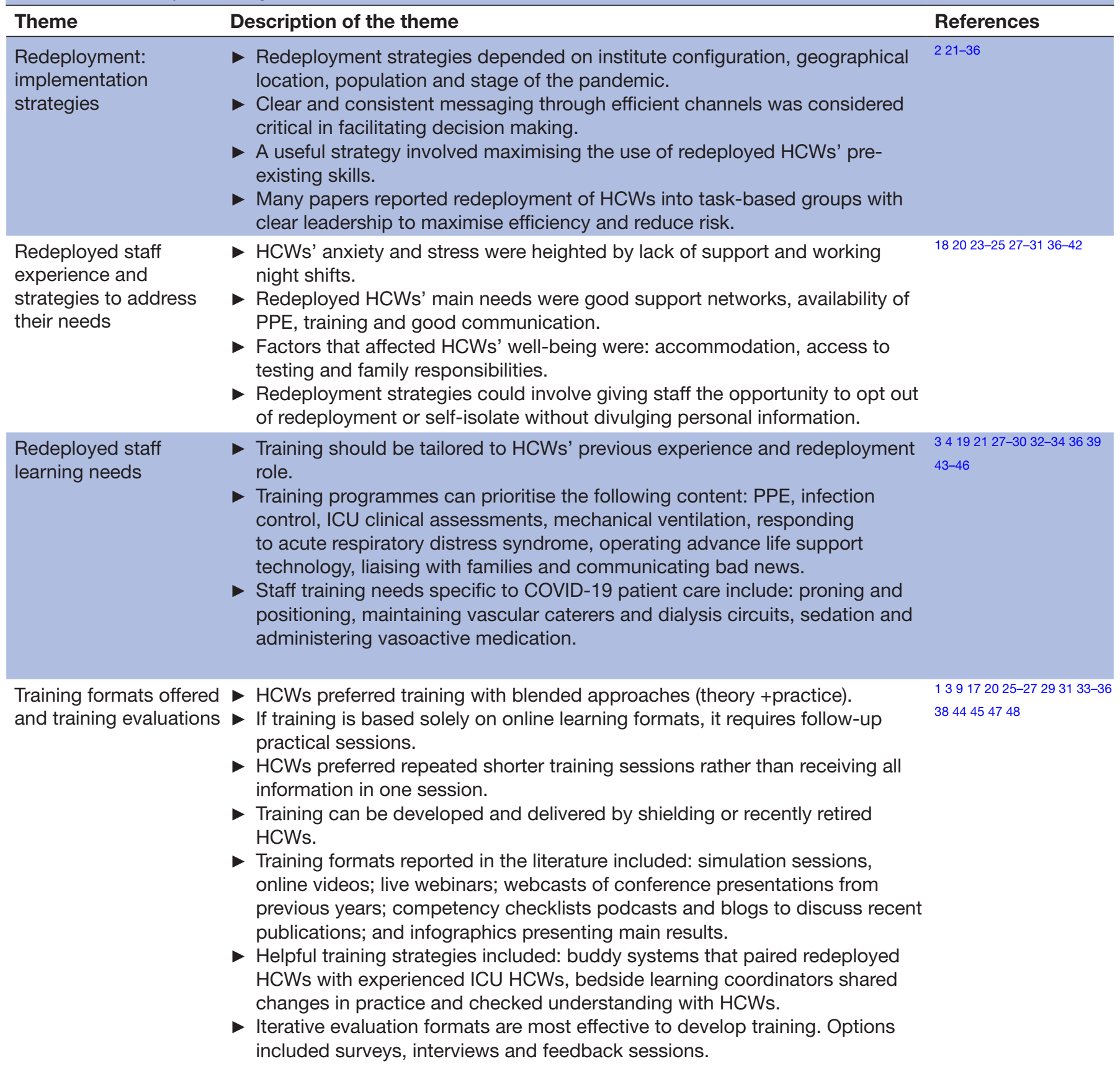

$\begin{array}{lll}\text { Future redeployment } & \text { Redeployment for future patient surges can be based on a stepwise } \\ \text { and training concerns } & \text { approach to redeployment; only redeploying discrete teams based on skills. } \\ & \text { Training needs to continue after redeployment to maintain skills (using } \\ & \text { blended approaches)Future training is likely to focus on patient rehabilitation. }\end{array}$

HCW, healthcare worker; ICU, intensive care unit; PPE, personal protective equipment.

Guidelines developed by National Health Service (NHS) England and NHS Improvement (2020a) proposed addressing redeployed HCWs' needs by placing more experienced HCWs on nightshifts; encouraging questions; providing psychological support; accepting lower turnaround of patients; and addressing issues about limited common areas and constant revision of rota patterns. One paper argued that HCWs should be given the opportunity to opt out of redeployment and self-isolate without divulging any personal information. ${ }^{43}$

Theme 3: redeployed HCWs' learning needs

Redeployed HCWs' learning needs varied depending on their previous experience and redeployment role. 
Training needed to be targeted at the right level of difficulty depending on HCWs' most recent work experience and focused solely on content that was relevant for redeployed roles. An example of prioritising learning objectives was teaching non-specialists to recognise worsening conditions and the need for ventilation, while specialists mastered details of the operation of ventilators. ${ }^{44}$

Across the literature, training needs considered essential to provide critical care services included learning the basics of ICU monitoring such as conducting and interpreting systematic clinical assessments; mechanical ventilation; response to acute respiratory distress syndrome (ie, intubation and cardiac arrest); and conducting lung ultrasounds, management of circulatory shock and operating advanced life support technology (eg, refs 2834 44).

Additionally, HCWs providing care specifically to patients with COVID-19 required an introduction to diagnosis and anticipated patient needs. These included prone and positioning, maintaining vascular catheters and dialysis circuits, sedation and administering vasoactive medication and continuous positive airway pressure services. ${ }^{4} 83333745-47$ Redeployed HCWs were also often asked to liaise with families and required training on communicating bad news. ${ }^{20} \mathrm{~A}$ particular emphasis was made on learning needs related to PPE and infection control, especially during aerosol-generating procedures. ${ }^{3} 30404477$ Regarding the latter, studies reflected on the difficulty of ensuring HCW safety due to permanently changing and sometimes conflicting advice on the use of PPE. ${ }^{331}$ As a result, teams assigned aerosol-generating procedures such as intubation were preferably staffed with experienced airway experts such as anaesthetists or otorhinolaryngologists to minimise the personnel required and the aerosolisation of the virus during procedures. ${ }^{22}$

\section{Theme 4: training formats offered and training evaluations}

Most courses reported in the literature included blended approaches (theory+practice) and were collaboratively designed by a variety of clinical educators, intensive care experts and frontline HCWs. ${ }^{1} 2632$ 34-36 3945464849 HCWs found it particularly useful when course content and practical sessions were repeated over time in consecutive sessions, rather than receiving an overwhelming amount of information in one session. ${ }^{18}$ This required allocating time to access training on a continuous basis and making sure it was kept up to date. ${ }^{42}$

Some of the training development and delivery was carried out by HCWs who were shielding or had recently retired. ${ }^{46}$ Elder clinicians or those with other risk factors for severe COVID-19 infection contributed to the pandemic response by leading simulation-based education sessions. Training formats included simulation sessions; online videos; live webinars; webcasts of conference presentations from previous years; competency checklists, podcasts and blogs to discuss recent publications; and infographics presenting main results. ${ }^{9} 212728303235373945$ Online learning formats allowed HCWs to access material at their own pace and check understanding; however, there was a need for practical follow-up sessions to consolidate learning. ${ }^{1} 1846$

In addition, courses were generally complemented by buddy systems (pairing up redeployed HCWs with more experienced ICU HCWs) or other similar set-ups to provide support for redeployed HCWs during clinical practice. ${ }^{3} 18323537$ Most training programmes were evaluated through surveys or interviews, and one article reported the use of cycles of iteration composed of daily interactive feedback sessions with tutors and candidates to enable rapid improvement. ${ }^{46}$ Another article shared the role of bedside learning coordinators, who updated HCWs on any new changes to protocols and checked their understanding of these updates. ${ }^{26}$

Innovations in the peer review process and format of presenting results helped to disseminate scientific evidence in a timely way. ${ }^{9}$ However, reaching a consistent message for best practice was a significant challenge during the pandemic and affected training development. Guidelines recommended teaching principles rather than strict procedures to allow for adaptability to the local context and as circumstances changed. ${ }^{2}$

\section{Theme 5: future redeployment and training delivery}

As the pandemic evolved, the numbers of patients with COVID-19 fluctuated rapidly and a need to return to 'business as usual' when possible was noted in the literature. ${ }^{424}$ For this reason, redeployment implementation strategies started to focus on facilitating de-escalating and escalating redeployment when necessary. Examples of practices that allowed for greater flexibility were the stepwise approach to redeployment, or only redeploying discrete teams based on skills (as described in the theme redeployment: implementation strategies and learning). ${ }^{3} 3243$

Regarding training, a need for balance between e-learning and face-to-face learning was mentioned. While e-learning was considered to have significant advantages such as a lower cost and reduced environmental impact, many felt there was still a need for face-toface learning. There were aspects of in-person meetings that enhanced learning and well-being such as social interaction, hands-on teaching and the opportunity to travel and visit venues. ${ }^{9}$ Lastly, Camilleri et $a t^{46}$ pointed out that as COVID-19 cases evolve, training focus will shift to rehabilitation.

\section{Proposed key principles for successful redeployment and training} Four key principles for successful redeployment emerged from the findings in this review: (1) developing HCW work groups based on skills rather than specialty; (2) maximising the use of redeployed HCWs' transferable skills to minimise training; (3) having a supportive work environment, including continuous support from more experienced HCWs; and (4) developing flexible arrangements that allowed for scaling redeployment up or down.

Inductions and sustained training were key. These should be targeted at the right level depending on HCWs' previous experience. Central training content included 
the basics of ICU monitoring, response to acute respiratory distress syndrome, proning and positioning, and PPE donning and doffing. HCWs assessed blended training (online+in-person practical sessions) taught in consecutive sessions in a positive way.

The implementation of these principles depended on each individual institution's context, facilities, equipment and the stage of the pandemic.

\section{DISCUSSION}

This review synthesised data from 40 studies to identify the core aspects of redeployment implementation, redeployed HCWs' experiences and training during the first year and a half of the COVID-19 pandemic.

To our knowledge, this is the first review of literature about redeployment and training during this pandemic. Key strengths of this work include following the systematic approach of PRISMA guidelines and combining authors with systematic review as well as clinical expertise. Searches were conducted in a wide range of databases, including grey literature and preprint servers, which have been important sources of information during the pandemic. However, searches were restricted from December 2019 to 16 July 2021. The review will have missed literature published outside of these dates and not included in these databases. It is possible that some studies from nonEnglish speaking countries were not identified due to all the search terms being in English. It is also important to mention that most of the included papers were from high-income countries, limiting our exploration of the experiences of low-income and middle-income countries.

The challenges faced by redeployed HCWs during the COVID-19 pandemic overlapped with previous studies assessing experiences of junior HCWs in emergency departments or HCWs redeployed to disaster and war zones. ${ }^{50-52}$ Theyyunni et $a l^{5353}$ analysed reflections from medical students after their emergency medicine rotation. The most common themes involved novice anxiety around critically ill patients and intubation procedures, miscommunication with other HCWs and challenges stemming from the tension between textbook medicine and complex social situations. Challenges specific to the current pandemic were PPE use and everchanging guidelines, and the paucity of testing at the initial stages. ${ }^{234}$ PPE use resulted in difficulties with communication, responding to emergencies in a timely manner and increased physical burden. ${ }^{55}$ Also, frontline HCWs mentioned that not having testing available increased their anxiety about possibly infecting their families and exacerbated their guilt when being off work due to suspected COVID-19 infections that could not be confirmed. ${ }^{6}$ Other challenges included aspects outside of clinical practice that had an impact on redeployed HCWs' well-being, such as access to breakout rooms, safety in lonely streets during stricter lockdowns and family caring responsibilities. ${ }^{66}$ Overall, effective healthcare leadership was found to consist of identifying and understanding the sources of fear and anxiety among individuals and designing strategies to mitigate their effects. ${ }^{23}$

The essential role of training and need for innovative approaches has also been highlighted in the literature from previous virus outbreaks. ${ }^{57}$ Multimodal, multidisciplinary and realistic simulation delivered in consecutive sessions were recommended options for successful training. ${ }^{49}{ }^{58-60}$ Doulias et a ${ }^{6161}$ summarised changes in surgical training during the COVID-19 pandemic. Key aspects of successful training overlapped with those identified for redeployment to ICU. The necessary shift to e-learning was possible due to innovative and collaborative approaches that mitigated the loss of access to other modes of learning during this time. In particular, interactive surgical simulation platforms offered a model of mentoring and continued guidance. Consultants were more available to impart simulation training and engage in discussions with trainees due to the reduced elective surgery services.

Recommendations for future redeployment plans included a shift towards flexible, innovative and adaptive workforce management approaches. In the UK, the initial focus of the NHS response to COVID-19 was establishing critical care capacity; this is now shifting towards developing pathways to support people to continue their rehabilitation and assessment in community settings. ${ }^{4}{ }^{4}$ This will require that HCWs receive training on regular remote monitoring, communication with patients and families and remote end-of-life care.

\section{CONCLUSION}

Tackling ongoing challenges for healthcare provision in the current pandemic will require intense collaboration from multidisciplinary teams to build organisational resilience and optimise resources through successful execution of redeployment and training. Literature about healthcare provision in disaster contexts and war zones is the closest example of rapid redeployment to emergency care and can be a source of useful recommendations. However, the COVID-19 pandemic presents unique challenges and has resulted in original and innovative approaches, which have been analysed in this review.

The key principles of redeployment distilled from our findings can inform future practice for redeployment and training in ICU settings within the evolving context of COVID-19 and future pandemics. Furthermore, similar strategies could be implemented to mitigate the negative effects of the workforce shortage crisis that affects many countries around the world.

\section{Author affiliations}

${ }^{1}$ Rapid Research Evaluation and Appraisal Lab (RREAL), University College London, London, UK

${ }^{2}$ Health Service and Population Research, King's College London Institute of Psychiatry Psychology and Neuroscience, London, UK

${ }^{3} 33 \mathrm{~N}$ Ltd, London, UK

${ }^{4}$ University Hospitals Birmingham NHS Foundation Trust, Birmingham, UK

${ }^{5}$ London North West University Healthcare NHS Trust, London, UK 
${ }^{6}$ Anaesthetics Department, St Bartholomew's Hospital, London, UK

Twitter Norha Vera San Juan @NorhaVera and Cecilia Vindrola-Padros @ CeciliaVindrola

Contributors NVSJ has acted as the guarantor of the study, led the conception and design, acquisition of data, analysis, interpretation, drafting and revision of the manuscript. CV-P contributed to the conception and design, acquisition of data, analysis, interpretation and drafting the manuscript. GC and SEC contributed to the acquisition of data, analysis, interpretation and drafting the manuscript. MC, JPJ and $\mathrm{AM}$ contributed to the conception and design, interpretation and drafting the manuscript.

Funding The study was funded by Health Education England (HEE), through $33 \mathrm{~N}$. Study funders contributed to the design, interpretation of the data and the writing of the report. Researchers conducted data collection and initial analysis independently from funders.

Competing interests None declared.

Patient consent for publication Not applicable.

Ethics approval This study does not involve human participants.

Provenance and peer review Not commissioned; externally peer reviewed.

Data availability statement Data are available on reasonable request. All data relevant to the study are included in the article or uploaded as supplementary information.

Supplemental material This content has been supplied by the author(s). It has not been vetted by BMJ Publishing Group Limited (BMJ) and may not have been peer-reviewed. Any opinions or recommendations discussed are solely those of the author(s) and are not endorsed by BMJ. BMJ disclaims all liability and responsibility arising from any reliance placed on the content. Where the content includes any translated material, BMJ does not warrant the accuracy and reliability of the translations (including but not limited to local regulations, clinical guidelines, terminology, drug names and drug dosages), and is not responsible for any error and/or omissions arising from translation and adaptation or otherwise.

Open access This is an open access article distributed in accordance with the Creative Commons Attribution Non Commercial (CC BY-NC 4.0) license, which permits others to distribute, remix, adapt, build upon this work non-commercially, and license their derivative works on different terms, provided the original work is properly cited, appropriate credit is given, any changes made indicated, and the use is non-commercial. See: http://creativecommons.org/licenses/by-nc/4.0/.

\section{ORCID iDs}

Norha Vera San Juan http://orcid.org/0000-0002-8677-7341

Georgia Chisnall http://orcid.org/0000-0002-1524-4564

Cecilia Vindrola-Padros http://orcid.org/0000-0001-7859-1646

\section{REFERENCES}

1 Hettle D, Sutherland K, Miles E, et al. Cross-skilling training to support medical redeployment in the COVID-19 pandemic. Future Healthc J 2020;7:e41-4.

2 NHS England, NHS Improvement. Clinical guide for the management of surge during the coronavirus pandemic: rapid learning. version 2, 2020. Available: https://www.england.nhs.uk/coronavirus/secondarycare/other- [Accessed 14 Dec 2020].

3 Doyle J, Smith EMJS, Gough CJR, et al. Mobilising a workforce to combat COVID-19: an account, reflections, and lessons learned. $J$ Intensive Care Soc 2020;368:175114372097154.

4 NHS England, NHS Improvement. COVID-19: deploying our people safely, 2020. Available: www.england.nhs.uk/coronavirus/workforce [Accessed 9 Jan 2021].

5 Faderani R, Monks M, Peprah D, et al. Improving wellbeing among UK doctors redeployed during the COVID-19 pandemic. Future Healthc J 2020;7:e71-6.

6 Vera San Juan N, Aceituno D, Djellouli N, et al. Mental health and well-being of healthcare workers during the COVID-19 pandemic in the UK: contrasting guidelines with experiences in practice. BJPsych Open 2021;7:e15.

7 Priede A, López-Álvarez I, Carracedo-Sanchidrián D, et al. Mental health interventions for healthcare workers during the first wave of COVID-19 pandemic in Spain. Revista de Psiquiatría y Salud Mental 2021;14:83-9.
8 Salem J, Hawkins L, Sundaram A, et al. COVID-19 and the impact on doctor wellbeing and training. The Physician 2020;6:1-8.

9 Fawcett WJ, Charlesworth M, Cook TM. Education and scientific dissemination during the COVID-19 pandemic. Anaesthesia2020:anae.15185.

10 Moher D, Liberati A, Tetzlaff J, et al. Preferred reporting items for systematic reviews and meta-analyses: the PRISMA statement. Ann Intern Med 2009;151:264

11 Ouzzani M, Hammady H, Fedorowicz Z, et al. Rayyan-a web and mobile APP for systematic reviews. Syst Rev 2016;5:210.

12 Tyndall J. AACODS checklist, 2010. Available: http://dspace.flinders. edu.au/dspace/

13 Popay J, Roberts H, Sowden A. Guidance on the conduct of narrative synthesis in systematic reviews. A Prod from ESRC methods Program Version 2006;1:b92.

14 Braun V, Clarke V. Using thematic analysis in psychology. Qual Res Psychol 2006;3:77-101.

15 Gale NK, Heath G, Cameron E, et al. Using the framework method for the analysis of qualitative data in multi-disciplinary health research. BMC Med Res Methodol 2013;13:117.

16 Barnett-Page E, Thomas J. Methods for the synthesis of qualitative research: a critical review. BMC Med Res Methodol 2009;9:59.

17 Noblit GW, Hare RD. Meta-ethnography : synthesizing qualitative studies. Sage Publications, 1988

18 Marks S, Edwards S, Jerge EH. Rapid deployment of critical care nurse education during the COVID-19 pandemic. Nurse Lead 2021:19:165-9.

19 Khajuria A, Tomaszewski W, Liu Z, et al. Workplace factors associated with mental health of healthcare workers during the COVID-19 pandemic: an international cross-sectional study. BMC Health Serv Res 2021;21:262.

20 Payne A, Rahman R, Bullingham R, et al. Redeployment of surgical trainees to intensive care during the COVID-19 pandemic: evaluation of the impact on training and wellbeing. J Surg Educ 2021;78:813-9.

21 Danielis M, Peressoni L, Piani T, et al. Nurses' experiences of being recruited and transferred to a new sub-intensive care unit devoted to COVID-19 patients. J Nurs Manag 2021;29:1149-58.

22 Shipchandler TZ, Nesemeier BR, Schmalbach CE, et al. Otolaryngologists' Role in Redeployment During the COVID-19 Pandemic: A Commentary. Otolaryngol Head Neck Surg 2020;163:94-5.

23 Panda N, Sinyard RD, Henrich N, et al. Redeployment of Health Care Workers in the COVID-19 Pandemic: A Qualitative Study of Health System Leaders' Strategies. J Patient Saf 2021;17:256-63.

24 George I, Salna M, Kobsa S, et al. The rapid transformation of cardiac surgery practice in the coronavirus disease 2019 (COVID-19) pandemic: insights and clinical strategies from a centre at the epicentre. Eur J Cardio-Thoracic Surg 2020;58:667-75.

25 Panda N, Sinyard RD, Henrich N, et al. Redeployment of health care workers in the COVID-19 pandemic: a qualitative study of health system leaders' strategies. J Patient Saf 2021;17:256-63.

26 Bohmer R, Shand J, Allwood D. Learning Systems : Managing. NEJM Catal Innov Care Deliv 2020.

27 Shi J, Giess CS, Martin T, et al. Radiology workload changes during the COVID-19 pandemic: implications for staff redeployment. Acad Radiol 2021;28:1-7.

28 Leng C, Challoner T, Hausien O, et al. From chaos to a new norm: the Birmingham experience of restructuring the largest plastics department in the UK in response to the COVID-19 pandemic. J Plast Reconstr Aesthet Surg 2020;73:2136-41.

29 Siva N, Knight P, Deep A. COVID-19: trainee perspectives from unprecedented changes on the paediatric intensive care unit (PICU). Pediatr Res 2021. doi:10.1038/s41390-021-01418-5. [Epub ahead of print: 02 Mar 2021].

30 Wells CM, Zhang Z, Spano-Szekely L, et al. Tiered model of nurse staffing for critical care and emergency departments in the wake of a pandemic. J Nurs Adm 2021;51:E1-5.

31 Vranas KC, Golden SE, Mathews KS, et al. The influence of the COVID-19 pandemic on ICU organization, care processes, and frontline clinician experiences: a qualitative study. Chest 2021;160:1714-28

32 KCE Belgian Health Care Knowledge Centre. Assessing the management of hospital surge capacity in the first wave of the COVID-19 pandemic in Belgium, 2020.

33 Doussot A, Ciceron F, Cerutti E, et al. Prone positioning for severe acute respiratory distress syndrome in COVID-19 patients by a dedicated team: a safe and pragmatic reallocation of medical and surgical work force in response to the outbreak. Ann Surg 2020;272:e311. 
34 Raith EP, Luoma AMV, Earl M, et al. Repurposing a neurocritical care unit for the management of severely ill patients with COVID-19: a retrospective evaluation. J Neurosurg Anesthesiol 2021;33:77-81.

35 Uchida E, Long-Fazio B, Marshall J, et al. Rising to the challenge: pharmacy residents on the front lines during COVID-19 pandemic. Am J Heal Pharm 2020;77:2101-6.

36 Hickey S, Mathews KS, Siller J, et al. Rapid deployment of an emergency department-intensive care unit for the COVID-19 pandemic. Clin Exp Emerg Med 2020;7:319-25.

37 Chiu M, Goldberg A, Moses S, et al. Developing and implementing a dedicated prone positioning team for mechanically ventilated ARDS patients during the COVID-19 crisis. Jt Comm J Qual Patient Saf 2021;47:347-53.

38 Khusid JA, Weinstein CS, Becerra AZ, et al. Well-Being and education of urology residents during the COVID-19 pandemic: results of an American national survey. Int J Clin Pract 2020;74:e13559.

39 Ch'ang JH, Ford J, Cifrese L, et al. Preparing neurology residents and advanced practice providers for the COVID-19 ICU-A neurocritical care led intervention. Neurohospitalist 2021;11:342-7.

40 D'souza B, Shetty A, Apuri N, et al. Adapting a secondary Hospital into a makeshift COVID-19 Hospital: a strategic roadmap to the impending crisis. Int J Healthc Manag 2020;13:346-51.

41 Lim C, De Silva I, Moussa G, et al. Redeployment of ophthalmologists in the United Kingdom during the coronavirus disease pandemic. Eur J Ophthalmol 2021;31:2268-74.

42 Coughlan C, Nafde C, Khodatars S, et al. COVID-19: lessons for junior doctors redeployed to critical care. Postgrad Med $J$ 2021;97:188-91.

43 Burnett GW, Katz D, Park CH, et al. Managing COVID-19 from the epicenter: adaptations and suggestions based on experience. $J$ Anesth 2021;35:1-8.

44 Kuang M, Wu J, Luo Y. Training and reployment of non-specialists is an effective solution for the shortage of health care workers in the COVID-19 pandemic. medRxiv2020:2020.07.17.20156117.

45 Yuriditsky E, Horowitz JM, Nair S, et al. Simulation-Based uptraining improves provider comfort in the management of critically ill patients with COVID-19. J Crit Care 2021;61:14-17.

46 Camilleri M, Zhang X, Norris M. Covid-19 ICU remote-learning course (CIRLC): rapid ICU remote training for frontline health professionals during the COVID-19 pandemic in the UK. J Intensive Care Soc 2020;175114372097263.

47 Robinson RE, Nightingale R, Frost F, et al. The rapid development and deployment of a new multidisciplinary CPAP service outside of a critical care environment during the early stages of the COVID-19 pandemic. Future Healthc J 2021;8:e156-9.

48 Jansen G, Latka E, Behrens F, et al. [Hospital paramedic. An interprofessional blended learning concept to qualify paramedics and medical personnel for deployment in intensive care units and emergency departments during the COVID-19 pandemic]. Anaesthesist 2021;70:13-22.

49 Riggall VK, Smith CM. Creating a sustainable, interprofessional-team training program: initial results. Clin Nurse Spec 2015;29:147-55.

50 Brewer TL, Ryan-Wenger NA. Critical care air transport team (CCATT) nurses' deployed experience. Mil Med 2009;174:508-14.

51 Marion D, Charlebois PB, Kao R. The healthcare workers' clinical skill set requirements for a uniformed international response to the Ebola virus disease outbreak in West Africa: the Canadian perspective. $J R$ Army Med Corps 2016;162:207-11.

52 Craven RM. Managing anaesthetic provision for global disasters. $\mathrm{Br} \mathrm{J}$ Anaesth 2017;119:1126-34.

53 Theyyunni N, House J, Seeyave D, et al. Understanding Medical Students' Struggles to be a Doctor in the Emergency Department. Ann Emerg Med 2013;62:S121.

54 Hoernke K, Djellouli N, Andrews L, et al. Frontline healthcare workers' experiences with personal protective equipment during the COVID-19 pandemic in the UK: a rapid qualitative appraisal. BMJ Open 2021;11:46199.

55 Scott M, Unsworth J. Lessons from other disciplines about communication, human performance and situational awareness while wearing personal protective equipment. SAGE Open Nurs 2020;6:237796082096376.

56 Regenold N, Vindrola-Padros C. Gender Matters: A Gender Analysis of Healthcare Workers' Experiences during the First COVID-19 Pandemic Peak in England. Soc Sci 2021:10:43.

57 Gertler M, Loik S, Kleine C, et al. [West Africa Ebola outbreak immediate and hands-on formation: the pre-deployment training program for frontline aid workers of the German Red Cross, other aid organizations, and the German Armed Forces, Wuerzburg, Germany 2014/15]. Bundesgesundheitsblatt Gesundheitsforschung Gesundheitsschutz 2018;61:394-403.

58 Darby D, Whiting D, Winters J. Multi-Modal training for adult ICU nurses caring for paediatric patients in a war zone. Intensive Care Med 2011;37.

59 El Khamali R, Mouaci A, Valera S, et al. Effects of a multimodal program including simulation on job strain among nurses working in intensive care units: a randomized clinical trial. JAMA 2018;320:1988.

60 Ellington LE, Becerra R, Mallma G, et al. Knowledge acquisition and retention after a high flow training programme in Peru: a quasi-experimental single group pre-post design. BMJ Open 2020;10:e035125.

61 Doulias T, Gallo G, Rubio-Perez I, et al. Doing more with less: surgical training in the COVID-19 era. J Invest Surg 2022;35:1-9.

62 NHS England, NHS Improvement, Health Education England. Advice on acute sector workforce models during COVID-19, 2020. Available: https://www.england.nhs.uk/coronavirus/wp-content/uploads/sites/ 52/2020/12/C0833 advice-on-acute-sector-workforce-modelsduring-COVID_with-apps_10dec.pdf [Accessed 11 Jan 2021]. 